\title{
Prospective study of bilateral mix-and- match implantation of diffractive multifocal intraocular lenses in Koreans
}

\author{
Chan Min Yang ${ }^{1 \dagger}$, Dong Hui Lim ${ }^{1,2 \dagger}$, Sungsoon Hwang ${ }^{1}$, Joo Hyun ${ }^{3}$ and Tae-Young Chung ${ }^{1 *}$
}

\begin{abstract}
Background: To evaluate monocular and binocular visual outcomes for near, intermediate, and far distance in patients implanted with diffractive multifocal intraocular lenses (IOLs) with different add power contralaterally.

Methods: This is a prospective contralateral study. Two diffractive multifocal IOLs with different added power were implanted bilaterally in twenty patients. TECNIS ${ }^{\oplus}$ ZKBOO $(+2.75 \mathrm{D})$ was implanted in a dominant eye, and TECNIS ${ }^{\odot}$ ZLB00 (+ 3.25 D) was implanted in a non-dominant eye. Uncorrected distance visual acuity (UDVA), uncorrected intermediate visual acuity (UIVA), uncorrected near visual acuity (UNVA), and manifest refraction (MR) values were measured at 1 month and 3 months postoperatively. At the 3-month follow-up, defocus curve, contrast sensitivity, and reading performance were evaluated. Quality of vision, overall satisfaction, and spectacle independence were evaluated by questionnaire.
\end{abstract}

Results: Postoperative binocular UDVA, visual acuity at $80 \mathrm{~cm}, 60 \mathrm{~cm}, 50 \mathrm{~cm}, 43 \mathrm{~cm}, 33 \mathrm{~cm}$ were $-0.08 \pm 0.10,0.12 \pm 0.14$, $0.09 \pm 0.09,0.07 \pm 0.11,0.14 \pm 0.09,0.25 \pm 0.11 \log M A R$. The binocular defocus curve showed an extended range of good visual acuity with sharp vision being observed from $0 \mathrm{D}$ to $-2.50 \mathrm{D}$ defocus (logMAR $\leq 0.1$ ). Reading performance was significantly improved compared to baseline. All patients were spectacle-free at distance, and $94.74 \%$ of the patients did not require glasses for near and intermediate vision.

Conclusions: Mix-and-match implantation of diffractive multifocal IOLs with different add power provides an excellent wide range of vision, as well as high levels of visual quality and patient satisfaction.

Trial registration: ClinicalTrials.gov, NCT02556944,

https://clinicaltrials.gov/show/NCT02556944

\section{Background}

A monofocal intraocular lens (IOL) implanted after cataract extraction to replace the focusing power of the crystalline lens has a fixed focal length. Although patients can achieve a good uncorrected-distance visual acuity after monofocal IOL implantation, most patients need glasses for reading or other activities at close distance.

However, in recent years, the increasing use of smartphones and tablets and new leisure activities require a fast alternation of far and near distance tasks, also in

\footnotetext{
* Correspondence: tychung@skku.edu

${ }^{\dagger}$ Equal contributors

'Department of Ophthalmology, Samsung Medical Center, Sungkyunkwan University School of Medicine, \#81 Irwon-ro, Gangnam-gu, Seoul 06351, South Korea

Full list of author information is available at the end of the article
}

elderly people. So spectacle dependence after cataract surgery can be inconvenient in the daily life of patients. In order to solve both cataract and presbyopia simultaneously, a variety of intraocular lenses have been developed. Diffractive bifocal IOLs with various levels of additional power have been widely used for correcting presbyopia after cataract surgery. The additional power of diffractive bifocal IOLs was selected according to patients' lifestyle. Although diffractive bifocal IOL implantation is an effective way to satisfy patients who want to stop using their glasses after cataract surgery, it often results in visual symptoms, including diminished contrast sensitivity and dysphotopsia due to the IOLs' diffractive surface $[1,2]$. Other disadvantages of the implantation of bifocal IOLs is 
a suboptimal intermediate visual acuity compared to near and distance visual acuities [3, 4].

Diffractive trifocal IOLs aim to provide a wider range of spectacle independence especially at an intermediate distance compared to bifocal IOLs. Trifocal IOLs provide three foci to enhance intermediate visual acuity. However, the distribution of light energy for a third focus could negatively affect near and distance visual acuity [5]. Decreased contrast sensitivity and unwanted visual symptoms may also occur after trifocal IOLs implantation [6, 7].

Recently, several methods of combining different types IOLs have been introduced to meet the diverse needs of the patients $[8,9]$. And bilateral mix-and-match implantation of diffractive multifocal IOLs with different add power may be another option for enhancing intermediate visual acuity. However, previous studies of contralateral implantation of diffractive multifocal IOLs with different add power have used AcrySof IQ ReSTOR [10, 11].

The purpose of this study was to evaluate the clinical outcomes following bilateral mix-and-match implantation of the recently developed Tecnis diffractive bifocal IOLs with +2.75 and +3.25 add power.

\section{Methods}

This prospective, contralateral study comprised 20 patients affected by bilateral senile cataract. The study was approved by the Institutional Review Board of the Samsung Medical Center, and adhered to the tenets of the Declaration of Helsinki. Written informed consent was obtained from all patients.

The inclusion criteria were patients with bilateral senile cataract and the desire to be spectacle-free for all distances. Exclusion criteria were ages younger than 21 years, corneal astigmatism greater than $1.00 \mathrm{D}$, previous ocular surgery or trauma and ocular disease other than cataract. Hole-in-the card test was conducted in all patients for detection of dominant eye preoperatively.

The implanted IOLs were TECNIS ZKB00 (add power + 2.75 diopter [D], theoretical working distance $50 \mathrm{~cm}$; Abbott Medical Optics, Santa Ana, California, USA) and TECNIS ZLB00 (add power + 3.25D, theoretical working distance $42 \mathrm{~cm}$ ). The $+2.75 \mathrm{D}$ IOL was implanted in the dominant eye and that $+3.25 \mathrm{D}$ IOL in the non-dominant eye. Emmetropic intraocular lens power was selected from SRK/T, SRKII, Haigis, or Hoffer Q formulas according to corneal curvature, axial length and anterior chamber depth measured by IOLMaster version 5.4 (Carl Zeiss Meditec, Jena, Germany).

\section{Surgical technique}

One experienced surgeon (T.Y.C) performed all surgical procedures under topical anesthesia using a standardized sutureless phacoemulsification with a $2.75 \mathrm{~mm}$ clear corneal incision. Steep axis corneal incision was created in eyes with corneal astigmatism of more than $0.5 \mathrm{D}$, and temporal corneal incision was made in eyes with corneal astigmatism less than 0.5D. The non-dominant eye was operated first. After that contralateral surgery was performed at an interval of one week. Postoperative gatifloxacin and fluometholone $0.1 \%$ eye drops were used 4 times a day for 1 month.

\section{Patient evaluation}

Preoperatively, all patients underwent a complete ophthalmologic examination including corrected and uncorrected visual acuity, manifest refraction, slit-lamp bio-microscopy, and fundus examination.

Patients were evaluated postoperatively at 1 day, 1 week, and 1 and 3 months. At 1 and 3 months after surgery, corrected and uncorrected visual acuity, manifest refraction, defocus curve, contrast sensitivity, reading performance, and subjective satisfaction were examined.

All patients underwent measurement of corrected and uncorrected distance visual acuity at $5 \mathrm{~m}$ (CDVA and UDVA). Uncorrected intermediate visual acuities (UIVA) were measured at $60 \mathrm{~cm}$ and $80 \mathrm{~cm}$ and uncorrected near visual acuities (UNVA) at $33 \mathrm{~cm}, 43 \mathrm{~cm}$, and $50 \mathrm{~cm}$ using the ETDRS chart. All visual acuity were measured monocularly and binocularly.

Defocus curves were plotted by measuring the visual acuity under photopic condition at $5 \mathrm{~m}$, adding lenses in $0.5 \mathrm{D}$ increments from -4.0 to $+2.0 \mathrm{D}$.

Contrast sensitivity at $3,6,12$, and 18 cycles per degree was measured using a CSV-1000 chart (Vector Vision, Greenville, $\mathrm{OH})$ under photopic $\left(85 \mathrm{~cd}[\mathrm{~cd}] / \mathrm{m}^{2}\right)$ and mesopic $\left(\sim 3 \mathrm{~cd} / \mathrm{m}^{2}\right)$ conditions at 3 months after surgery. Results were converted in log units for statistical analysis using a specific table for the CSV-1000 [12].

At baseline and 3 months postoperatively, reading performance was measured using an iPad application at $50 \mathrm{~cm}$ [13]. The print size of the reading chart ranges from 1.0 to 0 logarithm of the minimal angle of resolution $(\log M A R)$. Average reading speed in words per minute (wpm) was calculated with the iPad application. Critical print size was defined as the last acuity measured before the reading speed was reduced below the $95 \%$ confidence interval of that individual's average reading speed [14]. Threshold print size was determined as the smallest print size that could be read and expressed in logarithm of the reading acuity determination $(\operatorname{logRAD})$.

One and three months after surgery, all patients were asked to complete the questionnaire regarding overall satisfaction, presence of visual artifacts, and dependency on spectacles for near, intermediate and far vision. Overall satisfaction was evaluated using 5 levels (very satisfied, satisfied, neither satisfied nor dissatisfied, unsatisfied, very unsatisfied). Severity of visual artifacts, divided into 4 levels (none, minimal, moderate and severe), were assessed using 
a Quality of Vision questionnaire [15]. Furthermore, patients were asked if they would choose the same IOL again.

\section{Statistical analysis}

All data are presented as mean \pm standard deviation. The statistical analysis was performed using SPSS software version 18.0 (SPSS, Inc., Chicago, IL). Measured decimal visual acuities were converted to $\log M A R$ for data analysis. Because the variables did not follow a normal distribution, non-parametric statistical analysis was used. The Wilcoxon signed-rank test was applied to assess the difference between preoperative and postoperative data. The Mann-Whitney U test was used to compare the dominant and non-dominant eyes. A sample size of 17 patients would allow the detection of a minimum clinical relevant difference in depth of focus with a standard deviation of 5.8. The sample sizes took into account a significance level of $5 \%$ and a power of $80 \%$ for a 2 -sided test. Assuming an proportion of withdrawal of 10\%, 20 patients were included.

\section{Results}

A total of 20 patients were enrolled, of which 19 completed the study. Patient recruitment was from August 2015 to January 2016. The study was finished after 3 months postoperative follow-up visit was completed for all patients in April 2016. All patients received regular follow-up examinations for at least 3 months. The mean age was $60.1 \pm 6.61$ years (range: 45 to 70 years), $63.1 \%$ (12 of 19 ) of the patients were female. Preoperative mean axial length was $24.74 \pm 1.43 \mathrm{~mm}$ (range: $22.19 \mathrm{~mm}$ to $27.87 \mathrm{~mm}$ ), mean keratometric value was $43.18 \pm 1.25 \mathrm{D}$ (range: $40.91 \mathrm{D}$ to $45.18 \mathrm{D}$ ). Preoperative mean anterior chamber depth was $3.15 \pm 0.49 \mathrm{~mm}$ (range: $2.42 \mathrm{~mm}$ to $4.53 \mathrm{~mm}$ ). The mean IOL power implanted was $18.5 \pm$ 4.4 D (range: $7.5 \mathrm{D}$ to $25.5 \mathrm{D}$ ). Table 1 shows preoperative and postoperative monocular refractive results and visual acuities. At 3 months, there were statistically significant improvements in CDVA, UDVA, UIVA, and UNVA $(p<0.001)$. However, UNVA at $33 \mathrm{~cm}$ of eye with ZKB00 was not significantly different compared to the preoperative value $(p=0.178)$. No significant differences between eyes implanted with ZKB00 and eyes implanted with ZLB00 were found in uncorrected and corrected visual acuity at all distances $(p>0.05)$.

Table 2 shows preoperative and postoperative binocular visual acuities. Postoperative binocular visual acuities were significantly better than preoperative values, except for binocular UNVA at $33 \mathrm{~cm}$. Cumulative binocular UNVA, UIVA, and UDVA at 1 and 3 months after surgery are shown in Figs. 1, 2 and 3.

Monocular and binocular defocus curves are shown in Fig. 4. Eyes implanted with ZKB00 and ZLB00 had two peaks at 0 and $-2 \mathrm{D}$. When comparing both eyes,
ZKB00 eyes had a slightly better visual acuity from -1.0 to -2.0 D. However, these differences were not statistically significant $(p=0.84, p=0.103$ and $p=0.908$, respectively). Eyes with ZLB00 showed significantly better visual acuity at $-2.5,-3.0$, and $-3.5 \mathrm{D}$ compared to eyes implanted with ZKB00 ( $p=0.003, p=0.022$ and $\mathrm{p}=0.022$, respectively). The binocular defocus curve also showed two peaks and overlapping curves with monocular defocus curves, as well as a wider range of good visual acuity from 0 to $-3.0 \mathrm{D}(\log \mathrm{MAR}<0.2$ [range; $-0 \sim-3.0 \mathrm{D}$ ], $\log -$ MAR<0.1 [range: 0-2.5 D]) Eyes with ZKB00 had a slightly better visual acuity from -1.0 to -2.0 diopters (D) compared to eyes with ZLB00. Eyes with ZLB00 showed significantly better visual acuity at $-2.5,-3.0$, and - 3.5 D (Mann-Whitney $\mathrm{U}$ test, $p$ values $<0.05$ ). Binocular defocus curve showed good visual acuity better than 0.1 logMAR from 0 to $-2.5 \mathrm{D}$.

Postoperative contrast sensitivity at 3 months was statistically significantly better at some spatial frequencies than that measured preoperatively (Fig. 5).

The mean reading speed increased from $76.93 \pm$ $17.47 \mathrm{wpm}$ (range: 44.33 to $106.17 \mathrm{wpm}$ ) at baseline to $86.83 \pm 17.45 \mathrm{wpm}$ (range: 64.99 to $123.53 \mathrm{wpm}$ ) at 3 months after surgery. The mean critical print size decreased from $0.65 \pm 0.22 \log \mathrm{RAD}$ (range: 0.1 to 0.8 $\log \mathrm{RAD}$ ) at baseline to $0.24 \pm 0.13 \log \mathrm{RAD}$ (range: 0 to $0.5 \log \mathrm{RAD})$ at 3 months after surgery. The threshold print size also decreased from $0.35 \pm 0.22 \log \mathrm{RAD}$ (range: 0 to $0.8 \operatorname{logRAD}$ ) at baseline to $0.14 \pm 0.13 \operatorname{logRAD}$ (range: 0 to $0.4 \operatorname{logRAD}$ ) at 3 months after surgery. There were statistically significant differences in mean reading speed, critical print size, and threshold print size between baseline and 3 months after surgery $(p=0.07$, $p=0.01$ and $p=0.03$, respectively).

Overall satisfaction, visual symptoms and spectacle dependence are summarized in Table 3. Postoperative overall satisfaction with distance vision was statistically significant regarding the improvement achieved compared to preoperative $(p<0.05)$. Although halo and starburst were increased at 1 and 3 months after surgery, there were no significant differences compared to baseline (halo: $p=0.108$ and $p=0.301$, respectively; starburst: $p=0.890$ and $p=0.209$, respectively). All patients reported complete spectacle independence for distance after surgery. One patient required spectacles for near vision and another one patient sometimes for intermediate vision after surgery. A total of $94.7 \%$ of the patients (18 of 19) answered that they would choose the same IOLs again and $89.4 \%$ (17 of 19) did not feel dizzy and recognized the difference between both eyes.

\section{Discussion}

In this prospective study, the clinical outcomes of mix-and-match implantations of ZKB00 and ZLB00 


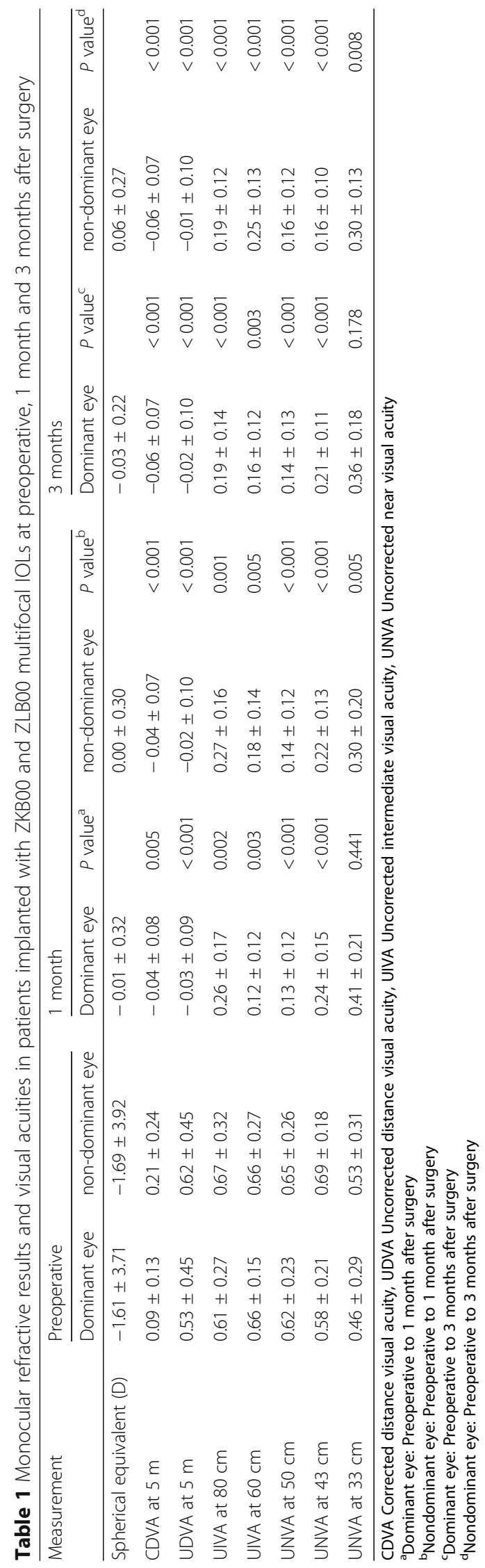


Table 2 Binocular visual acuities in patients implanted with ZKBOO and ZLBO0 multifocal IOLs at preoperative, 1 month and 3 months after surgery

\begin{tabular}{|c|c|c|c|c|c|}
\hline Measurements & Preoperative & 1 month & $p$ value $^{a}$ & 3 months & $p$ value $^{\mathrm{b}}$ \\
\hline CDVA at $5 \mathrm{~m}$ & $0.03 \pm 0.12$ & $-0.11 \pm 0.08$ & 0.001 & $-0.12 \pm 0.08$ & 0.001 \\
\hline UDVA at $5 \mathrm{~m}$ & $0.36 \pm 0.27$ & $-0.10 \pm 0.10$ & $<0.001$ & $-0.08 \pm 0.10$ & $<0.001$ \\
\hline UIVA at $80 \mathrm{~cm}$ & $0.50 \pm 0.27$ & $0.21 \pm 0.23$ & 0.013 & $0.12 \pm 0.14$ & $<0.001$ \\
\hline UIVA at $60 \mathrm{~cm}$ & $0.51 \pm 0.18$ & $0.10 \pm 0.14$ & 0.003 & $0.09 \pm 0.09$ & 0.003 \\
\hline UNVA at $50 \mathrm{~cm}$ & $0.43 \pm 0.19$ & $0.10 \pm 0.10$ & $<0.001$ & $0.07 \pm 0.11$ & $<0.001$ \\
\hline UNVA at $43 \mathrm{~cm}$ & $0.45 \pm 0.17$ & $0.16 \pm 0.15$ & $<0.001$ & $0.14 \pm 0.09$ & $<0.001$ \\
\hline UNVA at $33 \mathrm{~cm}$ & $0.31 \pm 0.30$ & $0.27 \pm 0.23$ & 0.491 & $0.25 \pm 0.11$ & 0.348 \\
\hline
\end{tabular}

CDVA Corrected distance visual acuity, UDVA Uncorrected distance visual acuity, UIVA Uncorrected intermediate visual acuity, UNVA Uncorrected near visual acuity aPreoperative to 1 month

${ }^{\mathrm{b}}$ Preoperative to 3 months

were showed good UCVA and UNVA as well as UIVA and high satisfaction without visual disturbance such as glare and halo. Although there was previous study comparing ZMB00, ZKB00 and ZLB00, we could confirm that depth of focus was increased through contralateral mix-and-match implantation of ZKB00 and ZLB00. Compared with previous studies using the trifocal diffractive IOLs, our results revealed that contrast sensitivity was not reduced and visual disturbance was less. The previous version, ZMB00 Tecnis multifocal IOLs with +4.0 D add power has the same design as the studied IOLs; however, the study IOLs have a relatively lower add power of $+2.75 \mathrm{D}$ and $+3.25 \mathrm{D}$. All IOLs of this platform have a refractive zone on the anterior surface to provide distance vision and a full diffractive posterior surface for near vision. The fewer diffractive rings of ZKB00 and ZLB00 compared to ZMB00 are considered to reduce unwanted visual symptoms [16].
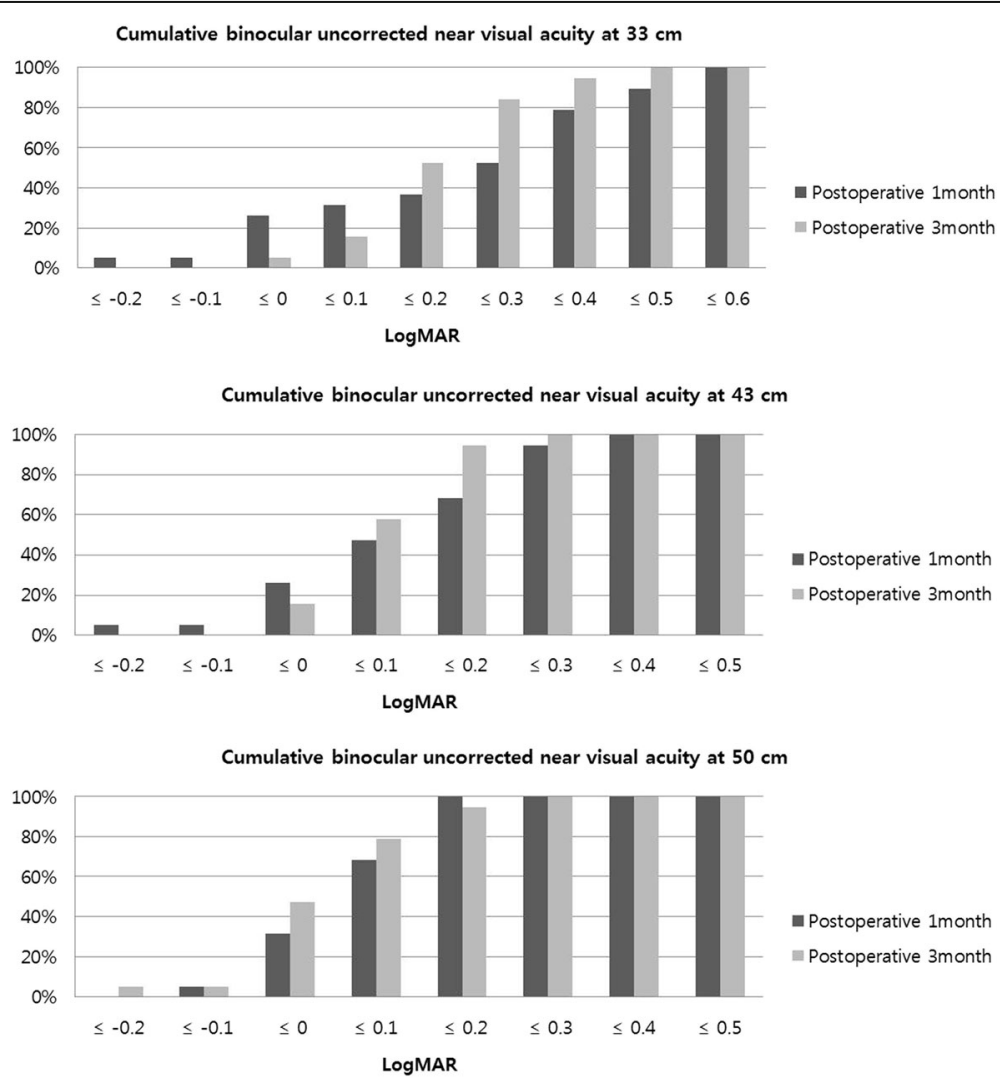

Fig. 1 Postoperative cumulative binocular uncorrected near visual acuity (UNVA) in patients implanted with ZKB00 and ZLB00 multifocal intraocular lens at $33 \mathrm{~cm}, 43 \mathrm{~cm}$, and $50 \mathrm{~cm}$ in logarithm of the minimal angle of resolution (logMAR) 
Cumulative binocular uncorrected intermediate visual acuity at $60 \mathrm{~cm}$

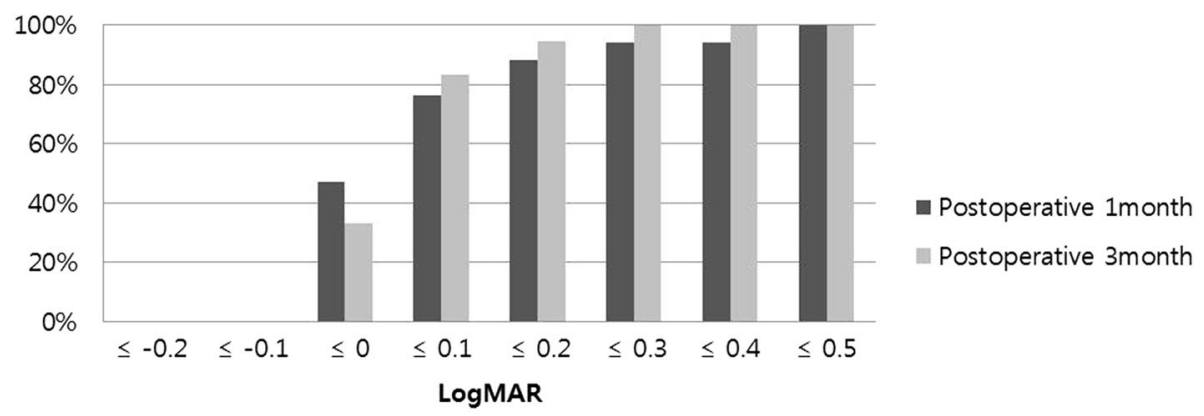

Cumulative binocular uncorrected intermediate visual acuity at $80 \mathrm{~cm}$

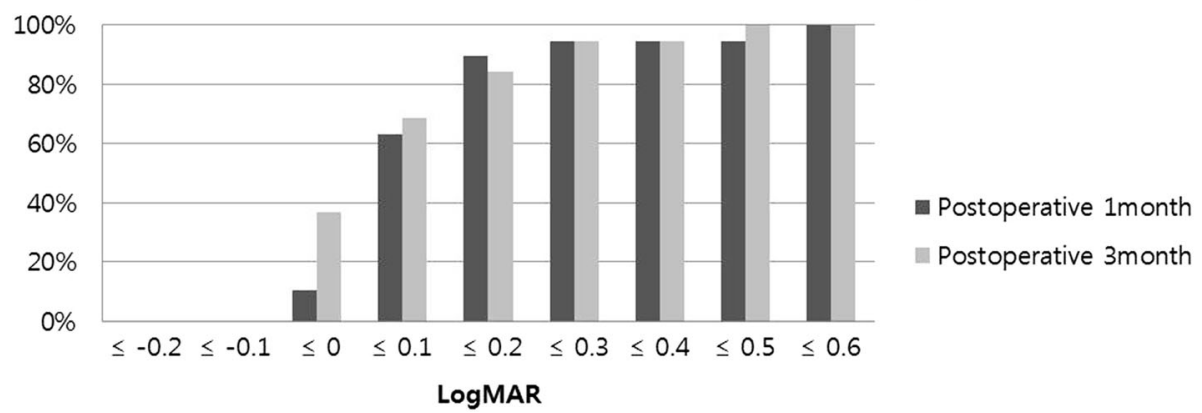

Fig. 2 Postoperative cumulative binocular uncorrected intermediate visual acuity (UIVA) in patients implanted with ZKB00 and ZLB00 multifocal intraocular lens at $60 \mathrm{~cm}$ and $80 \mathrm{~cm}$ in logarithm of the minimal angle of resolution (logMAR)

Regardless of pupil size, the light is evenly distributed between distance and near foci. Other optical principles of multifocal IOLs are dependent on pupil size [17].

Other studies with ZKB00 and ZLB00 IOL implantation report that subjects implanted with low add power bifocal IOLs had good intermediate and distance visual acuity with a high level of satisfaction [16, 18, 19]. Kretz et al. [19] reported $63.3 \%$ of the patients implanted with ZKB00 in both eyes achieved a binocular UIVA at $80 \mathrm{~cm}$ of $0.1 \log M A R$ or better. In this study, the percentage of patients with binocular logMAR UIVA better than $0.1 \log$ MAR at $80 \mathrm{~cm}$ was $68.5 \%$. Kretz et al. [18] reported that bilaterally implantation of the ZLB00 IOL revealed a binocular UIVA of $0.06 \pm 0.09 \log$ MAR at $60 \mathrm{~cm}$. In our study, we found comparable results with $0.09 \pm 0.09$ $\log$ MAR. However, previous studies did not include the defocus curve which makes it difficult to compare the achieved visual acuity at various distances directly. Previous studies of bilateral mix-and-match implantation of diffractive bifocal IOLs reported a better visual acuity over a wider range compared to bilateral implantation of IOLs with the same add power [11]. Our study with mix-and-match implantations of Tecnis ZKB00 and ZLB00 found a $0.1 \log$ MAR or better visual acuity in the 0 to $-2.5 \mathrm{D}$ range of the defocus curve. We could speculate that outcomes of mix-and-match implantation

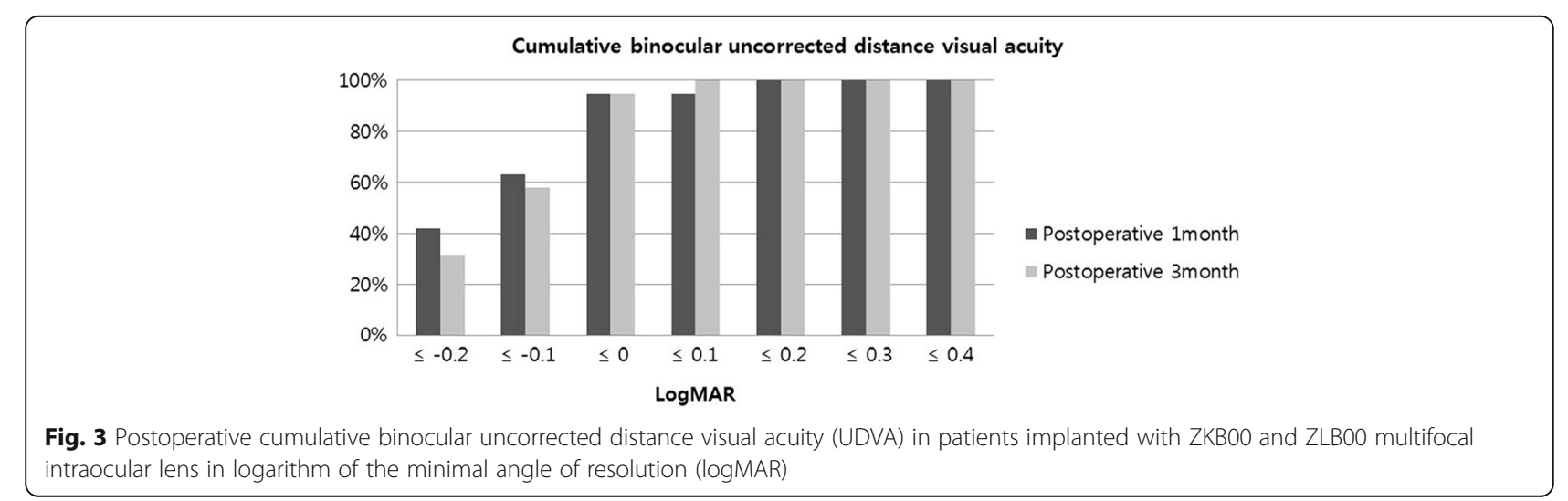




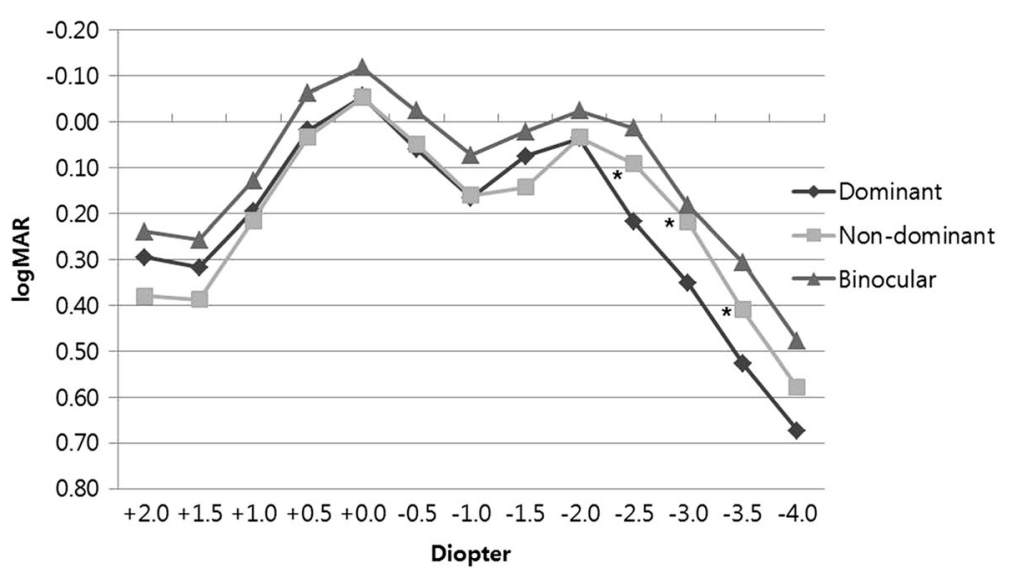

Fig. 4 Monocular and binocular defocus curve plotted in logarithm of the minimal angle of resolution (logMAR) in patients implanted with ZKB00 and ZLB00 multifocal intraocular lens at 3 months postoperatively. (*: $p<0.05$, between dominant and non-dominant eye)

of Tecnis ZKB00 and ZLB00 might be better visual acuity at a broader range than bilateral implantation of IOLs with the same add power (ZKB00 or ZLB00).

This study is the first prospective study applying the bilateral mix-and-match implantation of Tecnis ZKB00 and ZLB00. All previous studies on mix-and-match implantations of diffractive bifocal IOLs used the AcrySof ReSTOR IOL [10, 11]. Nakamura et al. [10] reported that contralateral implantation of ReSTOR IOLs with +
3.0 and +4.0 D addition was an effective way to get a broad range of good uncorrected visual acuity in the defocus curve. Mastropasqua R et al. [11] also reported that patients, implanted with ReSTOR IOLs with contralateral +2.5 and $+3.0 \mathrm{D}$ additions, had good uncorrected visual acuity over a wide range, and contrast sensitivity and visual quality did not decrease compared to bilateral implantation of diffractive multifocal IOLs with the same additional power. Compared with the

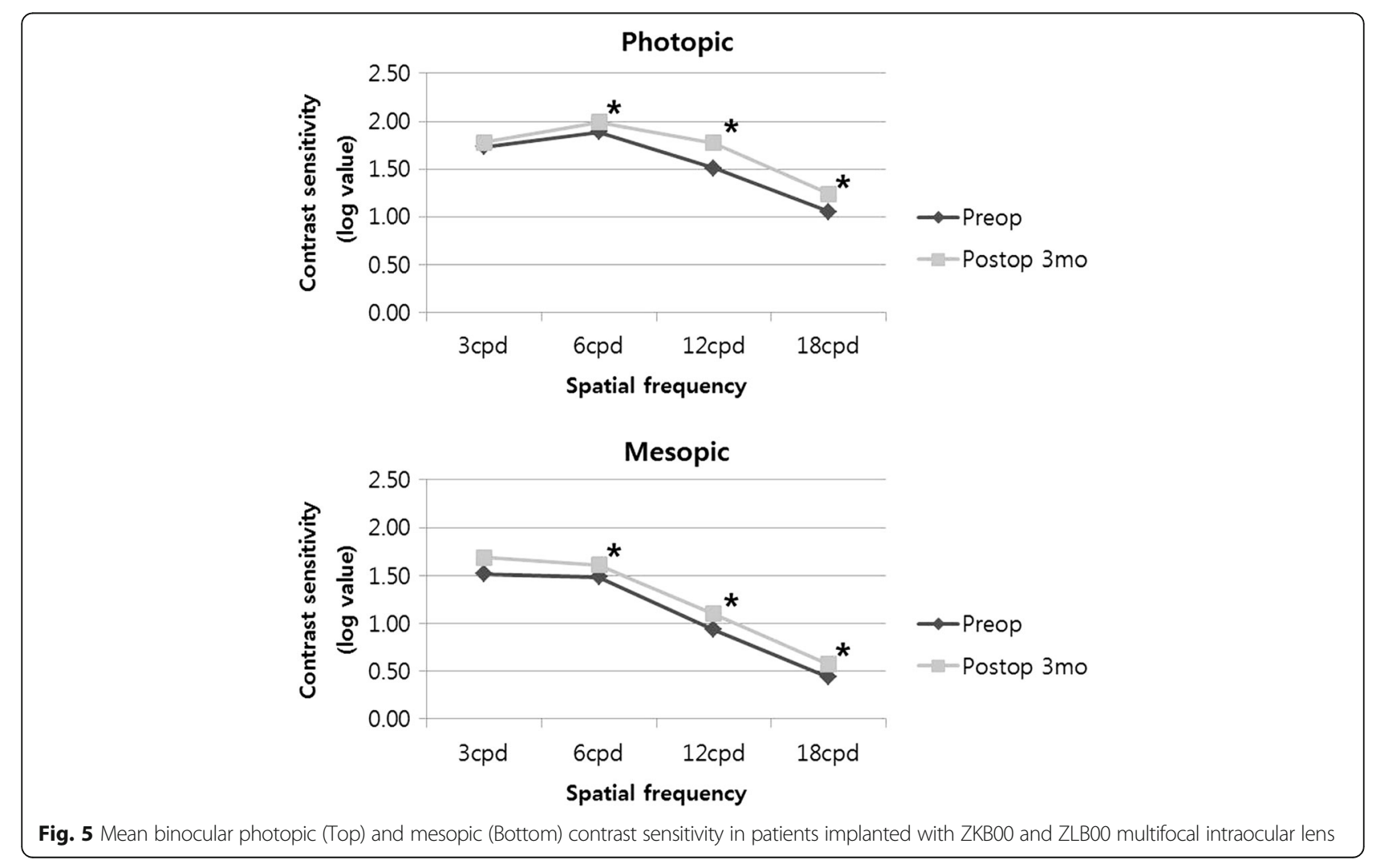


Table 3 Overall satisfaction, visual artifact questionnaire response and spectacle dependence in patients implanted with ZKB00 and ZLB00 multifocal IOLs at preoperative, 1 month and 3 months after surgery

\begin{tabular}{|c|c|c|c|c|c|}
\hline & Preoperative & 1 month & $p$ value $^{a}$ & 3 months & $p$ value $^{\text {b }}$ \\
\hline \multicolumn{6}{|c|}{ Overall satisfaction } \\
\hline Far & $2.68 \pm 0.89$ & $4.37 \pm 0.50$ & $<0.001$ & $4.42 \pm 0.51$ & 0.001 \\
\hline Intermediate & $2.68 \pm 0.89$ & $3.95 \pm 1.13$ & 0.003 & $4.11 \pm 0.81$ & 0.001 \\
\hline Near & $2.84 \pm 1.01$ & $3.84 \pm 0.90$ & 0.013 & $3.89 \pm 0.88$ & 0.008 \\
\hline \multicolumn{6}{|l|}{ Visual artifact } \\
\hline Glare & $0.47 \pm 1.02$ & $0.58 \pm 1.07$ & 0.777 & $0.21 \pm 0.71$ & 0.334 \\
\hline Halo & $0.47 \pm 1.02$ & $1.11 \pm 1.33$ & 0.108 & $0.84 \pm 1.12$ & 0.164 \\
\hline Starburst & $0.37 \pm 0.96$ & $0.32 \pm 0.75$ & 0.890 & $0.79 \pm 1.13$ & 0.179 \\
\hline \multicolumn{6}{|l|}{ Spectacle use } \\
\hline Far & $73.68 \%$ & $0.00 \%$ & $<0.001$ & $0.00 \%$ & $<0.001$ \\
\hline Intermediate & $78.94 \%$ & $5.26 \%$ & $<0.001$ & $5.26 \%$ & $<0.001$ \\
\hline Near & $63.16 \%$ & $5.26 \%$ & $<0.001$ & $5.26 \%$ & $<0.001$ \\
\hline
\end{tabular}

Overall satisfaction: 1 = very dissatisfied; 2 = dissatisfied; $3=$ neither satisfied nor dissatisfied; $4=$ satisfied; $5=$ very satisfied

Visual artifacts: $0=$ none; $1=$ minimal; $2=$ moderate; $3=$ severe

Visual artifact was assessed using the Quality of Vision questionnaire

${ }^{\text {a }}$ Preoperative to 1 month

${ }^{\mathrm{b}}$ Preoperative to 3 months

defocus curve of Mastropasqua et al., our study revealed $0.1 \operatorname{logMAR}$ or better vision from 0 to $-2.5 \mathrm{D}$, whereas Mastropasqua et al. report $0.1 \log$ MAR or better in the range from $0 \mathrm{D}$ and $-1.5 \sim-2.5 \mathrm{D}$. In the range of intermediated distance from $-0.5 \mathrm{D}$ to $-1.5 \mathrm{D}$, the results of ours study appear better than those of Mastropasqua et al. Although the add power differs slightly between studies, it seems that the IOL design is responsible for the better intermediate vision. And it may be due to differences in clinical characteristics of patients, such as axial length that can affect effective lens position.

Recently, trifocal diffractive IOLs were developed to provide better intermediate visual acuity. So far, no direct comparative study between bilateral implantation of diffractive trifocal IOLs and contralateral implantation of diffractive bifocal IOLs has been published. Ours study shows $0.1 \operatorname{logMAR}$ or better visual acuity in the range from 0 to $-2.5 \mathrm{D}$ in the defocus curve and it was comparable to or slightly better than that reported in previous studies on trifocal diffractive IOLs [20].

Multifocal IOLs had a drawback in decreasing contrast sensitivity However, for Tecnis multifocal IOLs it was known as the prolate anterior surface could improve the mesopic contrast sensitivity $[17,21]$. Gierek-Ciaciura et al. [22] reported that eyes with ZM900 Tecnis multifocal IOLs had better contrast sensitivity than eyes with other diffractive multifocal IOLs or refractive multifocal IOLs. Kim et al. [16] found that contrast sensitivity was higher in subjects with ZKB00 or ZLB00 than subjects with ZM900. This study, using ZKB00 and ZLB00, also showed improvement of contrast sensitivity compared with preoperative contrast sensitivity, and statistically significant improvement in some spatial frequency.

Diffractive multifocal IOLs with fewer diffractive rings and lower add power could theoretically improve the quality of vision after cataract surgery. Trifocal IOLs need it split more light energy to form the third focal point compared to bifocal IOLs and more diffractive rings are used for the trifocal IOLs compared to the IOLs used in our study. This might have an effect on the quality of vision for near and distanace [5-7]. Montes-Mico R et al. [5] used optical bench testing to confirm the quality of the apodized trifocal IOL (Finevision Micro F, PhysIOL, Liege, Belgium), and report a worse quality of vision compared bifocal diffractive IOLs. Kohnen $\mathrm{T}$ et al. [7] reported that halo and glare appeared in $60 \%$ and $28 \%$ of patients, respectively, after the implantation of AT LISA tri839MP, another trifocal IOL (Carl Zeiss Meditec, Jena, Germany). Our study showed halo and glare in $31.5 \%$ and $5.3 \%$ of patients, respectively, less visual artifacts compared to the results of Kohnen et al. Jonker et al. [6] also reported that mesopic contrast sensitivity was slightly decreased in eyes with diffractive trifocal IOLs compared to diffractive bifocal IOLs. Future studies should compare the quality of vision between groups with bilaterally implanted with diffractive trifocal IOLs and contralaterally implanted diffractive bifocal IOLs.

Reading performance, such as reading speed, critical print size, and threshold print size, were significantly improved postoperatively compared to baseline. Alfonso et al. [14] reported critical print size and threshold size after bilateral implantation of AcrySof +3.0 toric multifocal IOLs were 
$0.28 \pm 0.12 \log \mathrm{RAD}$ and $0.08 \pm 0.08 \log \mathrm{AD}$, respectively. Schmickler et al. [23] reported that critical print size was $0.27 \pm 0.12 \operatorname{logRAD}$ in patients after bilateral implantation of Tecnis ZMB00 + 4.0 diffractive multifocal IOLs. Our results of critical print size and threshold print size were $0.24 \pm 0.13 \log \mathrm{RAD}$ and $0.14 \pm 0.13 \log \mathrm{RAD}$, respectively, and comparable to previous studies [14, 23]. In our study, postoperative reading speed was $86.83 \pm$ $17.45 \mathrm{wpm}$. Alfonso et al. [14] reported a reading speed of $132.68 \pm 23.69 \mathrm{wpm}$ after the implantation of diffractive multifocal IOLs. Reading speed in our study is slightly lower compared to results from Western regions [14, 24]. One study using the same application as in our study to test reading speed in Koreans reported a reading speed of $129.7 \pm 25.9 \mathrm{wpm}$ for adults in their 20s and 30s [13] . Considering that the reading speed of young adults without presbyopia is faster than that of the older adults with presbyopia, it is possible that the difference in the testing method and characteristics of the languages are the reason for the variance between the results $[6,14,24]$.

When the overall satisfaction was evaluated on a fivepoint scale, satisfaction with distance, intermediate and near vision was $4.42 \pm 0.51,4.11 \pm 0.81$, and $3.89 \pm 0.88$, respectively. The results showed that most patients were satisfied. When patients were asked if they would choose the same IOLs again and if they would recommend the IOLs to others, $68.4 \%$ of the patients (13 of 19) would choose the same IOLs and recommend it to others.

In this study, ocular dominance was tested prior to cataract surgery, and ZKB00 (add power + 2.75D) was implanted in the dominant eyes and ZLB00 (add power + 3.25D) was implanted in the non-dominant eyes. We assumed that the 'relatively far' near focus (ZKBOO) in the dominant eye and 'relatively near' near focus (ZLB00) in the non-dominant eye would benefit according to the classic monovision trial. However, due to conflicting results with cross monovision results, it may be necessary to conduct additional research to compare the results with cross monovision [25]. Although both eyes of each patient were implanted with different add power, visual acuities of the dominant and non-dominant eyes at each distances were not statistically different. This may be due to the fact that difference in add power between the two IOLs was only $0.5 \mathrm{D}$. When patients were asked whether they could feel differences between eyes, 17 out of 19 patients did not perceive any difference between both eyes and they did not feel uncomfortable with it. It would be interesting to apply the mix-and-match technique using IOLs with an add power of $+2.75 \mathrm{D}$ and $+4.00 \mathrm{D}$.

The strength of this prospective contralateral study is the first study applying bilateral mix-and-match implantation of Tecnis multifocal IOLs. Second strength is visual acuities were measured at 6 different distances and that an objective measure of the expected vision at different distances was performed with a defocus curve. Previous studies measured intermediate and near visual acuity only at a single distance. And we comprehensively evaluate clinical outcomes including reading performance, contrast sensitivity and questionnaire. The limitation of this study is the missing direct comparison with bilaterally implanted IOLs with the same add power. However, the results of defocus curve of this study were good and not inferior to those of previous studies.

\section{Conclusions}

In conclusion, the mix-and-match technique using Tecnis multifocal IOLs with low add power is an effective way to achieve good visual acuity over a wide range without affecting quality of vision. The mix-and-match technique is an interesting option for patients who want to be spectacle-free after cataract surgery.

\section{Abbreviations \\ CDVA: Corrected distance visual acuity; IOL: Intraocular lens; logMAR: Logarithm of the minimal angle of resolution; logRAD: Logarithm of the reading acuity determination; MR: Manifest refraction; UDVA: Uncorrected distance visual acuity; UIVA: Uncorrected intermediate visual acuity; UNVA: Uncorrected near visual acuity; WPM: Words per minute}

\section{Acknowledgements}

None.

Funding

This research received no specific grant from any funding agency.

Availability of data and materials

The datasets of the current study are available from the corresponding author on reasonable request.

\section{Authors' contributions}

Involved in conception and design (DHL, T-YC) and conduct of the study (CMY, DHL, T-YC); collection, management and interpretation of data (CMY, $\mathrm{DHL}, \mathrm{SH}, \mathrm{JH})$; data analysis (CMY, DHL); writing the article (CMY, DHL); and preparation, review, and approval of the manuscript (CMY, DHL, T-YC). CMY and $\mathrm{DHL}$ contributed equally to the manuscript as the first authors. T-YC contributed to the manuscript as the corresponding authors.

\section{Ethics approval and consent to participate}

This study was performed in accordance with the tenets of the Declaration of Helsinki. Approval to conduct this study was obtained from the Institutional Review Board of the Samsung Medical Center (Seoul, Republic of Korea). Informed written consent was obtained from all participants.

\section{Consent for publication}

Not applicable.

\section{Competing interests}

No conflicts of interest and have no proprietary interest in any of the materials mentioned in this article.

\section{Publisher's Note}

Springer Nature remains neutral with regard to jurisdictional claims in published maps and institutional affiliations.

\section{Author details}

${ }^{1}$ Department of Ophthalmology, Samsung Medical Center, Sungkyunkwan University School of Medicine, \#81 Irwon-ro, Gangnam-gu, Seoul 06351, South Korea. ${ }^{2}$ Department of Preventive Medicine, Catholic University School 
of Medicine, Seoul, South Korea. ${ }^{3}$ Department of Ophthalmology, Saevit Eye Hospital, Goyang, South Korea.

Received: 19 December 2017 Accepted: 27 February 2018 Published online: 07 March 2018

\section{References}

1. Packer M, Chu YR, Waltz KL, et al. Evaluation of the aspheric tecnis multifocal intraocular lens: one-year results from the first cohort of the food and drug administration clinical trial. Am J Ophthalmol. 2010;149:577-84e1.

2. Ang R, Martinez G, Cruz E, et al. Prospective evaluation of visual outcomes with three presbyopia-correcting intraocular lenses following cataract surgery. Clin Ophthalmol. 2013:7:1811-23.

3. Maxwell WA, Cionni RJ, Lehmann RP, et al. Functional outcomes after bilateral implantation of apodized diffractive aspheric acrylic intraocular lenses with $\mathrm{a}+3.0$ or +4.0 diopter addition power Randomized multicenter clinical study. J Cataract Refract Surg. 2009;35:2054-61.

4. de Vries NE, Webers CA, Montes-Mico R, et al. Visual outcomes after cataract surgery with implantation of $\mathrm{a}+3.00 \mathrm{D}$ or $+4.00 \mathrm{D}$ aspheric diffractive multifocal intraocular lens: comparative study. J Cataract Refract Surg. 2010;36:1316-22.

5. Montes-Mico R, Madrid-Costa D, Ruiz-Alcocer J, et al. In vitro optical quality differences between multifocal apodized diffractive intraocular lenses. J Cataract Refract Surg. 2013;39:928-36.

6. Jonker SM, Bauer NJ, Makhotkina NY, et al. Comparison of a trifocal intraocular lens with a $+3.0 \mathrm{D}$ bifocal IOL: results of a prospective randomized clinical trial. J Cataract Refract Surg. 2015;41:1631-40.

7. Kohnen T, Titke C, Bohm M. Trifocal intraocular lens implantation to treat visual demands in various distances following lens removal. Am J Ophthalmol. 2016:161:71-7 e1.

8. Yoon SY, Song IS, Kim JY, et al. Bilateral mix-and-match versus unilateral multifocal intraocular lens implantation: long-term comparison. J Cataract Refract Surg. 2013;39:1682-90.

9. Pepose JS, Qazi MA, Davies J, et al. Visual performance of patients with bilateral vs combination Crystalens, ReZoom, and ReSTOR intraocular lens implants. Am J Ophthalmol. 2007;144:347-57.

10. Nakamura K, Bissen-Miyajima H, Yoshino M, et al. Visual performance after contralateral implantation of multifocal intraocular lenses with +3.0 and +4 . 0 diopter additions. Asia Pac J Ophthalmol (Phila). 2015;4:329-33.

11. Mastropasqua R, Pedrotti $E$, Passilongo $M$, et al. Long-term visual function and patient satisfaction after bilateral implantation and combination of two similar multifocal IOLs. J Refract Surg. 2015;31:308-14.

12. Schmitz S, Dick HB, Krummenauer F, et al. Contrast sensitivity and glare disability by halogen light after monofocal and multifocal lens implantation. Br J Ophthalmol. 2000;84:1109-12.

13. Song J, Kim JH, Hyung S. Validity of Korean version reading speed application and measurement of reading speed: pilot study. J Korean Ophthalmol Soc DE - 2016-04-28. 2016;57:642-9.

14. Alfonso JF, Knorz M, Fernandez-Vega $L$, et al. Clinical outcomes after bilateral implantation of an apodized $+3.0 \mathrm{D}$ toric diffractive multifocal intraocular lens. J Cataract Refract Surg. 2014;40:51-9.

15. McAlinden C, Pesudovs K, Moore JE. The development of an instrument to measure quality of vision: the quality of vision (QoV) questionnaire. Invest Ophthalmol Vis Sci. 2010;51:5537-45.

16. Kim JS, Jung JW, Lee JM, et al. Clinical outcomes following implantation of diffractive multifocal intraocular lenses with varying add powers. Am J Ophthalmol. 2015;160:702-9 e1.

17. Gil MA, Varon C, Rosello N, et al. Visual acuity, contrast sensitivity, subjective quality of vision, and quality of life with 4 different multifocal IOLs. Eur J Ophthalmol. 2012:22:175-87.

18. Kretz FT, Koss MJ, Auffarth GU. Intermediate and near visual acuity of an aspheric, bifocal, diffractive multifocal intraocular lens with +3.25 D near addition. J Refract Surg. 2015;31:295-9.

19. Kretz FT, Gerl M, Gerl R, et al. Clinical evaluation of a new pupil independent diffractive multifocal intraocular lens with a +2.75 D near addition: a European multicentre study. Br J Ophthalmol. 2015;99:1655-9.

20. Sheppard AL, Shah S, Bhatt U, et al. Visual outcomes and subjective experience after bilateral implantation of a new diffractive trifocal intraocular lens. J Cataract Refract Surg. 2013;39:343-9.
21. Cillino G, Casuccio A, Pasti M, et al. Working-age cataract patients: visual results, reading performance, and quality of life with three diffractive multifocal intraocular lenses. Ophthalmology. 2014;121:34-44.

22. Gierek-Ciaciura S, Cwalina L, Bednarski L, et al. A comparative clinical study of the visual results between three types of multifocal lenses. Graefes Arch Clin Exp Ophthalmol. 2010;248:133-40.

23. Schmickler S, Bautista CP, Goes F, et al. Clinical evaluation of a multifocal aspheric diffractive intraocular lens. Br J Ophthalmol. 2013;97:1560-4.

24. Alio JL, Plaza-Puche AB, Pinero DP, et al. Optical analysis, reading performance, and quality-of-life evaluation after implantation of a diffractive multifocal intraocular lens. J Cataract Refract Surg. 2011:37:27-37.

25. Jain $\mathrm{S}, \mathrm{Ou} \mathrm{R}$, azar DT. Monovision outcomes in presbyopic individuals after refractive surgery. Ophthalmology. 2001;108:1430-3.

\section{Submit your next manuscript to BioMed Central and we will help you at every step:}

- We accept pre-submission inquiries

- Our selector tool helps you to find the most relevant journal

- We provide round the clock customer support

- Convenient online submission

- Thorough peer review

- Inclusion in PubMed and all major indexing services

- Maximum visibility for your research

Submit your manuscript at www.biomedcentral.com/submit
) Biomed Central 